\title{
Persistence of type-specific human papillomavirus infection among Daqing City women in China with normal cytology: a pilot prospective study
}

\author{
Ni Li ${ }^{1, *}$, Dong Hang ${ }^{2, *}$, Lin Yang ${ }^{1,3}$, Xiaoshuang Feng ${ }^{1}$, Zhangyan Lyu ${ }^{1}$, Shuanghua \\ $\mathrm{Xie}^{1}$, Jing Zhou ${ }^{2}$, Lingying $\mathrm{Wu}^{4}$, Xiaoguang $\mathrm{Li}^{4}$, Nan $\mathrm{Li}^{4}$, Min Cheng ${ }^{4}$, Kai Zhang ${ }^{5}$, \\ Zhihui Zhang ${ }^{6}$, Hong Cui ${ }^{1}$, Jian Yin ${ }^{1,2}$, Zhibin Hu${ }^{2}$, Hongbing Shen ${ }^{2}$ and Min Dai ${ }^{1}$ \\ ${ }^{1}$ Program Office for Cancer Screening in Urban China, National Cancer Center/Cancer Hospital, Chinese Academy of Medical \\ Sciences and Peking Union Medical College, Beijing, China \\ ${ }^{2}$ Department of Epidemiology and Biostatistics, Collaborative Innovation Center of Cancer Medicine, School of Public Health, \\ Nanjing Medical University, Nanjing, China \\ ${ }^{3}$ Department of Hospital Infection Control, Beijing Jishuitan Hospital, Fourth Medical College of Peking University, Beijing, \\ China \\ ${ }^{4}$ Department of Gynecology Oncology, National Cancer Center/Cancer Hospital, Chinese Academy of Medical Sciences and \\ Peking Union Medical College, Beijing, China \\ ${ }^{5}$ Department of Cancer Prevention, National Cancer Center/Cancer Hospital, Chinese Academy of Medical Sciences and \\ Peking Union Medical College, Beijing, China \\ ${ }^{6}$ Department of Pathology, National Cancer Center/Cancer Hospital, Chinese Academy of Medical Sciences and Peking Union \\ Medical College, Beijing, China \\ *Authors contributed equally to this work
}

Correspondence to: Min Dai, email: daimin2002@hotmail.com Ni Li, email: lini1240@hotmail.com

Keywords: human papillomavirus, type-specific persistence, cervical cancer, prospective study
Received: October 13, 2016
Accepted: August 06, 2017
Published: August 11, 2017

Copyright: Li et al. This is an open-access article distributed under the terms of the Creative Commons Attribution License 3.0 (CC BY 3.0), which permits unrestricted use, distribution, and reproduction in any medium, provided the original author and source are credited.

\section{ABSTRACT}

Persistence of high-risk human papillomavirus (HPV) represents the necessary cause of cervical cancer. Researching natural history of HPV infection is important to identify high-risk population of cervical cancer. Since HPV infection is populationspecific, the findings in western populations could not be simply extended to Chinese and Asian females. This study investigated the type-specific persistence of HPV and related factors among Daqing City women in China. A total of 1759 women aged 18-80 years were enrolled at baseline. Cervical cell specimens were collected for cytological examination and HPV detection. HPV-positive individuals with normal cytology were followed up after 12 months. The results showed that HPV prevalence was $\mathbf{8 . 6 4 \%}$ at baseline, of which 85 HPV-positive cases with normal cytology were followed up. The one-year type-specific persistence of HPV and high-risk types were $34.12 \%(29 / 85)$ and $34.25 \%(25 / 73)$, respectively. The top three high-risk types were HPV16 (7/17, 41.18\%), HPV18 (5/8, 62.50\%) and HPV58 (7/15, 46.67\%). Age $>\mathbf{5 0}$ years was significantly associated with a higher risk of HPV persistence compared to $\leq 50$ (OR $=2.73 ; 95 \% \mathrm{CI}: 1.07,6.93)$. In conclusion, approximately one-third of Daqing City women with HPV infection had at least one-year viral persistence, most of which were high-risk types. Older age represents a risk factor of HPV persistence.

\section{INTRODUCTION}

With wide acceptance of human papillomavirus (HPV) as a necessary cause of cervical cancer [1], primary and secondary cervical cancer prevention strategies have moved towards detection and control of the virus. However, although approximately $80 \%$ of women will acquire an HPV infection during their life time [2], the 
majority of infections will be cleared and only a very small proportion can lead to cervical intraepithelial neoplasia (CIN) and cervical cancer. Persistent infection with highrisk oncogenic HPV, rather than transient infection, has been found to be the genuine factor associated with the development of cervical cancer [3]. Hence, although HPV DNA test is widely used as an adjuvant method of cytology examination for the identification of high-risk population of cervical cancer, many transient infections without oncogenic significance decrease the specificity of HPV DNA test. It is necessary to make a better understanding of HPV persistence for cost-effectiveness of HPV test in cervical cancer screening programs.

Several studies on persistent infection of HPV have been carried out in women from different countries, and revealed the persistence of HPV infection varied between $2.4 \%$ to $54 \%$ with $12-60$ months [4-10]. The large variation of the persistence estimates might be due to differences in definitions of persistence, the interval and length of follow-up, HPV DNA detection methods, and study populations. According to a published meta-analysis [11], most studies defined persistence as HPV positivity at two or more time points, whereas others used three or more HPV-positive visits, the proportion of HPV-positive visits, HPV positivity throughout follow-up, or time to clearance. Most studies included women with normal cytology at baseline, with the PCR and hybrid capture assay being the most commonly used methods to detect HPV. HPV16 is the most frequent type worldwide, whereas the distribution of other types varies geographically. For example, HPV18 is the second leading type in Europe and South America, while HPV52 and HPV58 are more dominant in Asia [12]. HPV16, 31, 33 and 52 were shown to be more persistent than other types [11].

HPV vaccination has not been administrated in China, and characterizing type-specific HPV persistence in the target population will benefit the evaluation of HPV vaccination effect in the future. Thus, we performed a prospective study to determine the type-specific HPV persistence, as well as potential risk factors in Daqing City women. To the best of our knowledge, this is the first population-based study on type-specific HPV persistence among Chinese women.

\section{RESULTS}

In the follow-up of 152 HPV-positive cases identified from 1759 participants at baseline, 67 (44.08\%) cases refused to participate after 12 months. But no significant difference in primary socio-demographics was found between those attending the follow-up and those refusing (all $P>0.05$, Table 1).

At baseline, the most prevalent types of HPV infection included HPV16 (1.88\%), HPV52 (1.65\%), HPV58 (1.08\%), and HPV18 (0.91\%) (Table 2). Excluding HPV types of very low prevalence $(<0.5 \%)$, we found that
HPV18 (62.50\%), HPV58 (46.67\%), and HPV16 (41.18\%) were the most common high-risk types of persistence.

The results of risk factors associated with HPV persistence were presented in Table 3. Age $>50$ years was significantly associated with a higher risk of HPV persistence compared to $\leq 50(\mathrm{OR}=2.73 ; 95 \% \mathrm{CI}: 1.07$, 6.93). However, we did not find significant associations of persistent infection with the other lifestyle factors.

\section{DISCUSSION}

In this prospective cohort, $8.6 \%$ of women aged 18-80 years had cervical infections of HPV at baseline survey. Follow-up data from HPV-positive women enabled us to estimate HPV persistence (34.1\%), with $34.3 \%$ persistence of high-risk types. We found that older age ( $>50$ years) was a risk factor for persistent infection. To our best knowledge, this study provided the first evidence on population-based type-specific HPV persistence in Chinese women.

Pooled analysis of the International Agency for Research on Cancer (IARC) HPV prevalence surveys showed variation of nearly 20 times $(1.4 \%-25.6 \%)$ in age-standardized HPV prevalence between different areas [13]. The reported prevalence in Asia was $8.7 \%$ (95\% CI: $7.9 \%-9.5 \%$ ) [13], similar to the data in our study $(8.6 \%)$. It was suggested that the persistence of HPV infection was approximately $30-50 \%$ with 12-months follow-up [7, 9, 10, 14]. In our prospective study, a similar persistence (34.1\%) was estimated among Daqing City women with normal cytology. HPV16 and HPV18 represent the most common oncogenic types worldwide, while HPV58 is more frequently detected in East Asia [15]. We also confirmed that HPV16, 18 and 58 infections were more likely to persist in our cohort.

Previous studies have suggested that both viral and host factors are implicated in persistent HPV infection [16]. In the aspect of virus, viral load, multiple infections, and certain types or variants were reported to influence HPV persistence [17-19]. Meanwhile, host factors such as number of sexual partners, condom use, oral contraceptive, and immunodeficiency have also been associated with the risk of HPV persistence [10, 20, 21]. In our study, we only found a significant association between age and persistent HPV infection, which was consistent with several previous studies $[5,7,22]$. One possible explanation for this association is that immune function is gradually weakened during aging, which may result in HPV evasion from host immune system [23]. Besides, prevalent infections in older women are also likely to represent those that have already persisted a long time. Because the numbers of women reporting to have high number of sexual partners, condom use, and oral contraceptives were all small in this study, other life-style related factors are needed to be identified. We also note that the associations with life-style related factors for HPV persistence remained insignificant after adjustment of the models for age. 
Table 1: Social-demographic characteristics between HPV-positive women who attended and who refused the follow-up

\begin{tabular}{|c|c|c|c|}
\hline Variable & $\begin{array}{c}\text { Follow-up }(n=85) \\
N(\%)\end{array}$ & $\begin{array}{c}\text { Lost }(n=67) \\
N(\%)\end{array}$ & $P^{*}$ \\
\hline Age (year) & & & 0.805 \\
\hline $20-34$ & $12(14.12)$ & $13(19.40)$ & \\
\hline $35-44$ & $37(43.53)$ & $23(34.33)$ & \\
\hline $45-54$ & $24(28.24)$ & $20(29.85)$ & \\
\hline $55-64$ & $9(10.59)$ & $8(11.94)$ & \\
\hline $65-79$ & $3(3.53)$ & $3(4.48)$ & \\
\hline Ethnicity & & & 0.385 \\
\hline Han & $80(95.24)$ & $65(98.48)$ & \\
\hline Others & $4(4.76)$ & $1(1.52)$ & \\
\hline Education & & & 0.327 \\
\hline High school and below & $34(40.48)$ & $32(48.48)$ & \\
\hline College and above & $50(59.52)$ & $34(51.52)$ & \\
\hline Marital status & & & 0.959 \\
\hline Single, widowed, or divorced & $15(17.86)$ & $12(18.18)$ & \\
\hline Married & $69(82.14)$ & $54(81.82)$ & \\
\hline Family monthly income (Chinese yuan) & & & 0.422 \\
\hline$<5000$ & $39(46.43)$ & $35(53.03)$ & \\
\hline$\geq 5000$ & $45(53.57)$ & $31(46.97)$ & \\
\hline Cigarette smoking & & & 0.385 \\
\hline No & $80(95.24)$ & 65 (98.48) & \\
\hline Yes & $4(4.76)$ & $1(1.52)$ & \\
\hline
\end{tabular}

HPV, human papillomavirus.

*The $\chi^{2}$ test was used.

The limitation of this study is that some persistent infections might be a re-infection with the same type due to the interval of approximately 12 months between baseline and follow-up. A shorter interval of HPV detection could improve the estimation of HPV persistence. However, repeat HPV testing at 12 months intervals is widely used in cervical screening programs to identify women at high risk of cervical precancerous lesion [24]. In addition, the sample size of our study is relatively small, which may limit the statistical power to identify risk factors. Strengths of our population-based study include the use of standardized in-person interviews conducted by trained interviewers in a private one-on-one setting that included detailed questions on sensitive risk behaviors and inclusion of only cytologically confirmed women with normal cervix in our study, which minimized the possibility of selection bias.

In conclusion, this pilot prospective study investigated the type-specific persistence of HPV among Daqing City women with normal cytology. Further largescale and long-term follow-up studies are warranted to improve targeted screening and effective prevention.

\section{MATERIALS AND METHODS}

\section{Study population and follow-up}

This prospective study was conducted in a community of the Sartu District, Daqing City, China. All mentally and physically competent women aged 18-80 years were invited to Daqing Aixin Hospital to participate in the baseline survey in 2010. After exclusion of 55 women refusing to participate, and 201 unmarried, pregnant or hysterectomized women who did not undergo gynecological examination and provide cervical cell specimens, a total of 1759 women were enrolled at baseline. According to the Bethesda 2001 nomenclature, a diagnosis by liquid-based cytology was assigned to each participant as having negative for intraepithelial lesion or malignancy (NILM) or having an epithelial cell abnormality such as atypical squamous cells of undetermined significance (ASCUS), low-grade squamous intraepithelial lesion (LSIL), high-grade squamous intra epithelial lesion (HSIL) and invasive cervical cancer (ICC). HPV DNA was detected in $152(8.64 \%)$ women with 
Table 2: Cervical type-specific persistence of HPV among women in Daqing City, China

\begin{tabular}{|c|c|c|c|c|}
\hline \multirow{2}{*}{ HPV type } & \multicolumn{2}{|c|}{ Baseline $(n=1759)$} & \multicolumn{2}{|c|}{ Follow-up $(n=85)$} \\
\hline & $N$ & Prevalence (\%) & $N$ & Persistence (\%) \\
\hline Any type & 152 & 8.64 & $29 / 85$ & 34.12 \\
\hline High-risk & 131 & 7.45 & $25 / 73$ & 34.25 \\
\hline HPV16 & 33 & 1.88 & $7 / 17$ & 41.18 \\
\hline HPV18 & 16 & 0.91 & $5 / 8$ & 62.50 \\
\hline HPV26 & 3 & 0.17 & $0 / 0$ & - \\
\hline HPV31 & 5 & 0.28 & $0 / 0$ & - \\
\hline HPV33 & 10 & 0.57 & $1 / 4$ & 25.00 \\
\hline HPV39 & 15 & 0.85 & $1 / 7$ & 14.29 \\
\hline HPV45 & 2 & 0.11 & $0 / 2$ & 0.00 \\
\hline HPV51 & 3 & 0.17 & $1 / 2$ & 50.00 \\
\hline HPV52 & 29 & 1.65 & $2 / 13$ & 15.38 \\
\hline HPV56 & 2 & 0.11 & $1 / 1$ & 100.00 \\
\hline HPV58 & 19 & 1.08 & $7 / 15$ & 46.67 \\
\hline HPV59 & 2 & 0.11 & $2 / 2$ & 100.00 \\
\hline HPV66 & 1 & 0.06 & $0 / 1$ & 0.00 \\
\hline HPV68 & 7 & 0.40 & $0 / 4$ & 0.00 \\
\hline Low-risk & 29 & 1.65 & $4 / 16$ & 25.00 \\
\hline HPV6 & 9 & 0.51 & $0 / 6$ & 0.00 \\
\hline HPV11 & 1 & 0.06 & $0 / 0$ & - \\
\hline HPV40 & 1 & 0.06 & $0 / 0$ & - \\
\hline HPV53 & 1 & 0.06 & $0 / 1$ & 0.00 \\
\hline HPV55 & 2 & 0.11 & $0 / 0$ & - \\
\hline HPV61 & 13 & 0.74 & $4 / 8$ & 50.00 \\
\hline HPV82 & 4 & 0.23 & $0 / 1$ & 0.00 \\
\hline
\end{tabular}

HPV, human papillomavirus.

normal cytology (NILM). Of them, 85 (55.92\%) women participated in the follow-up after 12 months. This study was approved by the ethics committee of Cancer institute and Hospital, Chinese Academy of Medical Sciences (CICAMS). All participants signed an informed consent form according to the recommendations of CICAMS.

\section{Socio-demographic and behavioral data}

All enrolled women were interviewed by well-trained nurses in a separate room in Daqing Aixin Hospital. The structured questionnaires included information on sociodemographic characteristics, reproductive and menstrual factors, sexual habits, and contraceptive methods.

\section{Cervical specimen collection and HPV DNA detection}

Gynecological examination and cervical cell collection were described in our previous studies [25]. TellgenplexTM
HPV DNA Test (Tellgen Life Science, Shanghai, China), a polymerase chain reaction (PCR)-based fluorescent Luminex assay [26] was applied to detect $24 \mathrm{HPV}$ types including 15 high-risk types (HPV16, 18, 26, 31, 33, 35, 39, 45, 51, 52, $56,58,59,66,68$ ) and 9 low-risk types (HPV6, 11, 40, 42, $44,53,55,61,82)$. Briefly, HPV DNA was amplified by multiplex PCR using biotin-labeled consensus PCR primers. The PCR products were then hybridized to sets of color-coded microspheres. Each set of microspheres was coated with a pre-designed HPV type-specific probe. After incubation with phycoerythrin-conjugated streptavidin, microspheres were read by using a Luminex 200 system (Luminex Corporation, TX, USA). HPV types were determined according to the unique fluorescent dye signature from each set of microspheres, when the signature value was $>150$.

\section{Statistical analysis}

The $\chi^{2}$ test was used to assess soci-demographic differences between individuals attending and refusing 
Table 3: Risk factors associated with type-specific HPV persistence

\begin{tabular}{|c|c|c|c|c|}
\hline Variable & No. of HPV persistence & No. of HPV transient infection & OR $(95 \%$ CI) & $\boldsymbol{P}$ \\
\hline \multicolumn{5}{|l|}{ Age (year) } \\
\hline$\leq 50$ & 10 & 33 & 1.00 & 0.033 \\
\hline$>50$ & 19 & 23 & $2.73(1.07,6.93)$ & \\
\hline \multicolumn{5}{|l|}{ Education } \\
\hline High school and below & 11 & 23 & 1.00 & 0.730 \\
\hline College and above & 18 & 32 & $1.18(0.47,2.96)$ & \\
\hline \multicolumn{5}{|l|}{ Marital status } \\
\hline Single, widowed, or divorced & 7 & 8 & 1.00 & 0.275 \\
\hline Married & 22 & 47 & $0.53(0.17,1.66)$ & \\
\hline \multicolumn{5}{|l|}{ Family monthly income (yuan) } \\
\hline$<5000$ & 14 & 25 & 1.00 & 0.805 \\
\hline$\geq 5000$ & 15 & 30 & $0.89(0.36,2.20)$ & \\
\hline \multicolumn{5}{|l|}{ Cigarette Smoking } \\
\hline No & 27 & 53 & 1.00 & 0.505 \\
\hline Yes & 2 & 2 & $1.96(0.26,14.71)$ & \\
\hline \multicolumn{5}{|l|}{ Alcohol Drinking } \\
\hline No & 26 & 53 & 1.00 & 0.217 \\
\hline Yes & 3 & 2 & $3.06(0.48,19.44)$ & \\
\hline \multicolumn{5}{|l|}{ Family history of cancer } \\
\hline No & 18 & 28 & 1.00 & 0.246 \\
\hline Yes & 10 & 27 & $0.58(0.23,1.47)$ & \\
\hline \multicolumn{5}{|l|}{ Age of menarche (year) } \\
\hline$\leq 15$ & 19 & 30 & 1.00 & 0.332 \\
\hline$>15$ & 10 & 25 & $0.63(0.25,1.60)$ & \\
\hline \multicolumn{5}{|l|}{ Regular menstrual cycle } \\
\hline Yes & 26 & 50 & 1.00 & 0.852 \\
\hline No & 3 & 5 & $1.15(0.26,5.21)$ & \\
\hline \multicolumn{5}{|l|}{ Age of first sexual behavior(year) } \\
\hline$\leq 24$ & 16 & 36 & 1.00 & 0.356 \\
\hline$>24$ & 13 & 19 & $1.54(0.61,3.86)$ & \\
\hline \multicolumn{5}{|l|}{ Number of sexual partners } \\
\hline 1 & 27 & 48 & 1.00 & 0.411 \\
\hline$\geq 2$ & 2 & 7 & $0.51(0.10,2.62)$ & \\
\hline \multicolumn{5}{|l|}{ Condom use } \\
\hline Ever & 6 & 9 & 1.00 & 0.483 \\
\hline Never & 18 & 41 & $0.66(0.20,2.13)$ & \\
\hline \multicolumn{5}{|l|}{ Oral contraceptive use } \\
\hline Ever & 1 & 1 & 1.00 & 0.591 \\
\hline Never & 23 & 49 & $0.47(0.03,7.84)$ & \\
\hline \multicolumn{5}{|l|}{ HPV at baseline } \\
\hline Single & 23 & 52 & 1.00 & 0.066 \\
\hline Multiple & 6 & 4 & $3.39(0.87,13.17)$ & \\
\hline
\end{tabular}

HPV, human papillomavirus; OR, odds ratio; CI, confidence interval. 
the follow-up. Odds ratios (ORs) for HPV persistence and corresponding 95\% confidence intervals (CIs) were calculated by logistic regression equations. All tests were two-sided and $P<0.05$ was defined as statistically significant.

\section{Abbreviations}

HPV: human papillomavirus; CIN: cervical intraepithelial neoplasia; NILM: negative for intraepithelial lesion or malignancy; ASCUS: atypical squamous cells of undetermined significance; LSIL: low-grade squamous intraepithelial lesion; HSIL: high-grade squamous intra epithelial lesion; ICC: invasive cervical cancer; OR: odds ratios; CI: confidence interval; IARC: International Agency for Research on Cancer.

\section{Author contributions}

Min Dai and Ni Li obtained financial support and were responsible for the study design. Dong Hang and Jing Zhou performed statistical analyses and participated in paper writing. Lin Yang, Xiaoshuang Feng, Zhangyan Lyu and Shuanghua Xie did questionnaire surveys and data collection. Lingying $\mathrm{Wu}$, Xiaoguang Li, Nan Li and Kai Zhang were responsible for clinical diagnosis. Min Cheng, Zhihui Zhang, Hong Cui and Jian Yin collected specimens. Hongbing Shen and Zhibin Hu contributed to result interpretation and paper revision.

\section{ACKNOWLEDGMENTS}

We acknowledge the support of Daqing Aixin Hospital by providing us with a suitable environment to perform questionnaire surveys and sample collection. We also thank Dr. Gary M Clifford, IARC, for his valuable discussions of the manuscript.

\section{CONFLICTS OF INTEREST}

The authors have declared that no conflicts of interest exist.

\section{FUNDING}

This work was supported by National Natural Science Foundation of China (grant no. 81373079, 81673265,81172757 and 81502873), PUMC Youth Fund (grant no. 3332016131), the scholarship from China Scholarship Council (CSC), and Natural Science Foundation of Jiangsu Province for Youth (grant no.BK20150997).

\section{REFERENCES}

1. Walboomers JM, Jacobs MV, Manos MM, Bosch FX, Kummer JA, Shah KV, Snijders PJ, Peto J, Meijer CJ,
Munoz N. Human papillomavirus is a necessary cause of invasive cervical cancer worldwide. J Pathol. 1999; 189: $12-19$.

2. Bosch FX, Manos MM, Munoz N, Sherman M, Jansen AM, Peto J, Schiffman MH, Moreno V, Kurman R, Shah KV. Prevalence of human papillomavirus in cervical cancer: a worldwide perspective. International biological study on cervical cancer (IBSCC) Study Group. J Natl Cancer Inst. 1995; 87:796-802.

3. Ho GY, Burk RD, Klein S, Kadish AS, Chang CJ, Palan P, Basu J, Tachezy R, Lewis R, Romney S. Persistent genital human papillomavirus infection as a risk factor for persistent cervical dysplasia. J Natl Cancer Inst. 1995; 87:1365-1371.

4. Bae J, Seo SS, Park YS, Dong SM, Kang S, Myung SK, Park SY. Natural history of persistent high-risk human papillomavirus infections in Korean women. Gynecol Oncol. 2009; 115:75-80.

5. Ferreccio C, Van De Wyngard V, Olcay F, Dominguez MA, Puschel K, Corvalan AH, Franceschi S, Snijders PJ. Highrisk HPV infection after five years in a population-based cohort of Chilean women. Infect Agent Cancer. 2011; 6:21.

6. Gyllensten U, Sanner K, Gustavsson I, Lindell M, Wikstrom I, Wilander E. Short-time repeat high-risk HPV testing by self-sampling for screening of cervical cancer. Br J Cancer. 2011; 105:694-697.

7. Mollers M, Boot Hein J, Vriend Henrike J, King Audrey J, van den Broek Ingrid VF, van Bergen Jan EA, Brink Antoinette AT, Wolffs Petra FG, Hoebe Christian JP, Meijer Chris JL, van der Sande Marianne AB, de Melker Hester E. Prevalence, incidence and persistence of genital HPV infections in a large cohort of sexually active young women in the Netherlands. Vaccine. 2013; 31:394-401.

8. Oakeshott P, Aghaizu A, Reid F, Howell-Jones R, Hay PE, Sadiq ST, Lacey CJ, Beddows S, Soldan K. Frequency and risk factors for prevalent, incident, and persistent genital carcinogenic human papillomavirus infection in sexually active women: community based cohort study. BMJ. 2012; 344:e4168.

9. Ralston Howe E, Li Z, McGlennen RC, Hellerstedt WL, Downs LS Jr. Type-specific prevalence and persistence of human papillomavirus in women in the United States who are referred for typing as a component of cervical cancer screening. Am J Obstet Gynecol. 2009; 200:245 e241-247.

10. Schmeink CE, Melchers WJ, Siebers AG, Quint WG, Massuger LF, Bekkers RL. Human papillomavirus persistence in young unscreened women, a prospective cohort study. Plos One. 2011; 6:e27937.

11. Rositch AF, Koshiol J, Hudgens MG, Razzaghi H, Backes DM, Pimenta JM, Franco EL, Poole C, Smith JS. Patterns of persistent genital human papillomavirus infection among women worldwide: a literature review and meta-analysis. Int J Cancer. 2013; 133:1271-1285. 
12. de Sanjose S, Quint WG, Alemany L, Geraets DT, Klaustermeier JE, Lloveras B, Tous S, Felix A, Bravo LE, Shin HR, Vallejos CS, de Ruiz PA, Lima MA, et al. Human papillomavirus genotype attribution in invasive cervical cancer: a retrospective cross-sectional worldwide study. Lancet Oncol. 2010; 11:1048-1056.

13. Clifford GM, Gallus S, Herrero R, Munoz N, Snijders PJ, Vaccarella S, Anh PT, Ferreccio C, Hieu NT, Matos E, Molano M, Rajkumar R, Ronco G, et al. Worldwide distribution of human papillomavirus types in cytologically normal women in the International Agency for Research on Cancer HPV prevalence surveys: a pooled analysis. Lancet. 2005; 366:991-998.

14. Rodriguez AC, Schiffman M, Herrero R, Wacholder S, Hildesheim A, Castle PE, Solomon D, Burk R. Rapid clearance of human papillomavirus and implications for clinical focus on persistent infections. J Natl Cancer Inst. 2008; 100:513-517.

15. Chan PK. Human papillomavirus type 58: the unique role in cervical cancers in East Asia. Cell Biosci. 2012; 2:17.

16. Wang SS, Hildesheim A. Chapter 5: Viral and host factors in human papillomavirus persistence and progression. J Natl Cancer Inst Monogr. 2003; 35-40.

17. Schiffman M, Rodriguez AC, Chen Z, Wacholder S, Herrero R, Hildesheim A, Desalle R, Befano B, Yu K, Safaeian M, Sherman ME, Morales J, Guillen D, et al. A population-based prospective study of carcinogenic human papillomavirus variant lineages, viral persistence, and cervical neoplasia. Cancer Res. 2010; 70:3159-3169.

18. Winer RL, Xi LF, Shen Z, Stern JE, Newman L, Feng Q, Hughes JP, Koutsky LA. Viral load and short-term natural history of type-specific oncogenic human papillomavirus infections in a high-risk cohort of midadult women. Int $\mathrm{J}$ Cancer. 2014; 134:1889-1898.

19. Trottier H, Mahmud S, Prado JC, Sobrinho JS, Costa MC, Rohan TE, Villa LL, Franco EL. Type-specific duration of human papillomavirus infection: implications for human papillomavirus screening and vaccination. J Infect Dis. 2008; 197:1436-1447.
20. Stensen S, Kjaer SK, Jensen SM, Frederiksen K, Junge J, Iftner T, Munk C. Factors associated with type-specific persistence of high-risk human papillomavirus infection: A population-based study. Int J Cancer. 2016; 138:361-368.

21. Ahdieh L, Klein RS, Burk R, Cu-Uvin S, Schuman P, Duerr A, Safaeian M, Astemborski J, Daniel R, Shah K. Prevalence, incidence, and type-specific persistence of human papillomavirus in human immunodeficiency virus (HIV)-positive and HIV-negative women. J Infect Dis. 2001; 184:682-690.

22. Rodriguez AC, Schiffman M, Herrero R, Hildesheim A, Bratti C, Sherman ME, Solomon D, Guillen D, Alfaro M, Morales J, Hutchinson M, Katki H, Cheung L, et al. Longitudinal study of human papillomavirus persistence and cervical intraepithelial neoplasia grade $2 / 3$ : critical role of duration of infection. J Natl Cancer Inst. 2010; 102:315-324.

23. Gonzalez P, Hildesheim A, Rodriguez AC, Schiffman M, Porras C, Wacholder S, Pineres AG, Pinto LA, Burk RD, Herrero R. Behavioral/lifestyle and immunologic factors associated with HPV infection among women older than 45 years. Cancer Epidemiol Biomarkers Prev. 2010; 19: 3044-3054.

24. Goodman A. HPV testing as a screen for cervical cancer. BMJ. 2015; 350:h2372.

25. Dai M, Bao YP, Li N, Clifford GM, Vaccarella S, Snijders PJ, Huang RD, Sun LX, Meijer CJ, Qiao YL, Franceschi S. Human papillomavirus infection in Shanxi Province, People's Republic of China: a population-based study. Br J Cancer. 2006; 95:96-101.

26. Oh Y, Bae SM, Kim YW, Choi HS, Nam GH, Han SJ, Park CH, Cho Y, Han BD, Ahn WS. Polymerase chain reaction-based fluorescent Luminex assay to detect the presence of human papillomavirus types. Cancer Sci. 2007; 98:549-554. 